\title{
Incidence of uveitis in Bantu-speaking negroes of South Africa
}

\author{
JEFFREY FREEDMAN
}

From the Department of Ophthalmology, University of the Witwatersrand, and the Baragwanath and St. John Eye Hospitals, South Africa

By studying uveitis in a defined population it was hoped that the aetiology of the condition might be elucidated. Epidemiological studies have seldom been applied to uveitis, such surveys having been mainly limited to trachoma, glaucoma, and keratoconjunctivitis. As regards the Bantu-speaking negroes of Southern Africa, only glaucoma has been studied to any great extent. It was hoped that, by a routine clinical examination, careful laboratory investigations, and immunological studies, an aetiological pattern could be found in persons from this group who were suffering from uveitis.

A routine series of investigations, as described below, was carried out on each patient. In addition, patients were randomly selected for special laboratory investigations, including immunological, chromosome, and histological studies.

Descriptive epidemiology measuring the risk of developing a disease in different populations also forms part of this study.

In the United States of America the prevalence of uveitis is about 200 per 100,000 population, with no specific geographical distribution. The frequency of uveitis has been assessed in Manchester (Stanworth, and McIntyre, I957), London (Smith and Ashton, I955), and Baltimore (Guyton and Woods, I94I), but the prevalence could not be worked out as the precise size of the population served by the hospitals where the work was done was unknown. The retrospective survey at Rochester (Darrell, Wagener and Kurland, I962) produced an almost complete collection of clinically identifiable cases of uveitis within a limited and defined population over a Io-year period. This enabled an accurate assessment of the prevalence of the disease in a well-defined area to be made.

A prospective study of the incidence of uveitis in Bantu-speaking negroes in the Johannesburg area of South Africa was carried out over a 2-year period. All patients admitted to the study were seen by the author at the St. John Eye Hospital, Baragwanath, where over 90 per cent. of ophthalmological problems in the Bantu-speaking negroes in the area are dealt with. The patients were selected from those attending the eye hospital, a diagnosis of uveitis being made by the criteria suggested by Hogan, Kimura, and Thygeson (1959). 


\section{Clinical methods}

Particulars of all patients were recorded on special charts indicating history, age, sex, ethnic group, clinical description of the disease in both eyes, and results of the special investigations and treatment. The patients were classified primarily as cases of anterior or posterior uveitis, the latter being diagnosed only in the presence of active or healed chorioretinitis. All cases of traumatic uveitis are excluded from this study.

\section{Results}

During the 2-year period May, I97I, to May, I973, 355 new cases of uveitis were seen in Bantu-speaking negroes. They were spread evenly throughout the year, no seasonal prevalence being noted. No correlation with occupation or habitat was found. The numbers represent an average of more than one new case every second day, no clinics being held on Saturdays or Sundays. There were $3^{\mathrm{I}} 7$ cases of anterior uveitis (Tables I and II) and $3^{8}$ cases of posterior uveitis (Table III).

Table I Anterior uveitis in males

\begin{tabular}{|c|c|c|c|}
\hline Age group (yrs) & Population & No. of patients & Rate per 100,000 \\
\hline $0-14$ & 84,526 & 14 & 8 \\
\hline $15-24$ & $83,5^{\text {I I }}$ & 33 & 19 \\
\hline $25-44$ & 82,665 & 75 & 45 \\
\hline $45-64$ & 66,654 & 40 & 30 \\
\hline $65^{-}$ & I 4,043 & 3 & IO \\
\hline Total & 331,399 & 165 & 25 \\
\hline
\end{tabular}

Table II Anterior uveitis in females

\begin{tabular}{|c|c|c|c|}
\hline Age group (yrs) & Population & No. of patients & Rate per 10о,0о0 \\
\hline $0-14$ & 90,712 & 26 & 14 \\
\hline I 5-24 & 75,985 & 19 & 12 \\
\hline $25-44$ & 89,705 & 73 & $4 I$ \\
\hline $45-64$ & 53,478 & 28 & 26 \\
\hline $65^{-}$ & 10,980 & 6 & 27 \\
\hline Total & $3^{20,860}$ & 152 & 23 \\
\hline
\end{tabular}

\section{Incidence}

The census figures for the Bantu-speaking negroes in the Johannesburg area were based on population statistics for June, 1972, as supplied by the Non-European Affairs Department of the City of Johannesburg.

The estimated population served predominantly by the St. John Eye Hospital was 6 52,259 Bantu-speaking negroes.

The incidence rate was calculated according to the method used by Darrell and others (1962) in the Rochester survey, i.e.

No. of new cases over 2-year period $\times 100,000$

2 years $\times$ population in area served by the hospital 
Table III Incidence of posterior uveitis

\begin{tabular}{|c|c|c|c|c|}
\hline \multirow[t]{2}{*}{ Age group (yrs) } & \multicolumn{2}{|l|}{ Males } & \multicolumn{2}{|l|}{ Females } \\
\hline & No. of patients & Rate per 100,000 & No. of patients & Rate per 100,000 \\
\hline $0-14$ & o & o & I & 4 \\
\hline $15^{-24}$ & 2 & I & I & 4 \\
\hline $25-44$ & I3 & 7 & 7 & 4 \\
\hline $45^{-64}$ & 4 & 3 & 9 & 8 \\
\hline 65 & $\mathbf{I}$ & 3 & 0 & 0 \\
\hline Total & 20 & & 18 & \\
\hline
\end{tabular}

Although the population figures given are probably too low for the total Johannesburg area, we feel that, for the purpose of this study, the figures are significant as they deal with the areas served by the St. John Eye Hospital, from which over 90 per cent. of the clinic patients are drawn. Certainly over 90 per cent. of the patients in the survey lived in the areas from which the census figures were taken.

The average annual incidence for all types of uveitis is thus 25 per roo,ooo population (Table IV). The rate rises to a peak in the age group 25 to 44 years (Tables I and II), and is lowest in the youngest age group although this was the largest group seen. The rate for posterior uveitis was low for both males and females (Table III), being highest in the 25 to 44-year group in males and in the older age group in females.

Table IV Incidence per Ioo,ooo population per year of all types of uveitis

\begin{tabular}{|c|c|c|c|}
\hline Age group (yrs) & No. of patients & Rate per 100,000 & Population \\
\hline $0-14$ & $4^{I}$ & II & 175,238 \\
\hline $15^{-24}$ & 55 & 17 & I 59,496 \\
\hline $25-44$ & I68 & 49 & I 72,370 \\
\hline $45^{-64}$ & $8 \mathrm{I}$ & 24 & 120,132 \\
\hline $65^{-}$ & Io & 20 & 25,023 \\
\hline Total & 355 & 25 & 652,259 \\
\hline
\end{tabular}

Anterior uveitis was much more common than posterior uveitis, and was almost equal in males and females. The incidence in the $65+$ age group in females is double that in males; the reason for this is unknown.

As only new cases were included in the calculations the incidence rate could be estimated separately from the prevalence rate which would include all cases of uveitis.

\section{Discussion}

We believe this to be the first report on the incidence of uveitis in an all-Negro population in a specific area. All the patients were seen by a single investigator, which ensured uniformity in diagnosis. The total incidence rate of 25 per I00,000 of the population is higher than that found in the Rochester study (Darrell and others, 1962), which was I 7 per Ioo,ooo. The peak incidence at 25 to 44 years is similar to that found in Rochester and may have some significance as regards the susceptibility of this age group. The rate for anterior uveitis 
(24 per 100,000) is significantly higher than the rate of 12 per 100,000 found in Rochester.

The sex incidence shows a slightly higher rate in males than females for anterior uveitis, but the ratio of $\mathrm{I}: 0 \cdot 8$ is small and statistically insignificant. Smith and Ashton (1955) found a higher incidence in females in their surveys. Another interesting feature is that I I per cent. of the total number of cases of anterior and posterior uveitis occurred in children. This is double the 5 per cent. found by Smith and Ashton and the 5.8 per cent found by Kimura, Hogan, and Thygeson (1954). Bennett (1955) found an incidence of only 2. I per cent. in children under 15 years of age.

The total incidence of posterior uveitis in the group studied was 3 per 100,000 of the population. This is similar to the number found in the Rochester survey. There was no significant difference in the incidence between males and females. According to Fajardo ( I969), however, posterior uveitis was more common in the Philippines.

\section{Conclusion}

The incidence of uveitis in the Johannesburg Bantu-speaking negro appears to be greater than in the Caucasoid group investigated in Rochester. As the Caucasoid population in Johannesburg do not attend any one specific hospital for their ocular complaints, a comparison of the incidence of uveitis in the Caucasoid and Negro populations of Johannesburg could not be made. Although not mentioned in this paper, no specific entity or entities were mainly responsible for the uveitis observed in this survey. It appeared to be of the anterior endogenous type, no aetiological factor being found. This is unlike the findings of other investigators dealing with totally negro populations. Onchocerciasis occurs as a common cause of uveitis in West Africa (Budden, I955), Perkins (rg68) stated that sarcoid appeared to be a frequent cause of uveitis in the Negro population of Baltimore, U.S.A., and Chesterton and Perkins (1967) stated that toxoplasmosis was a frequent cause of uveitis in Negro patients from the West Indies and West Africa.

Thus, in the Bantu-speaking negroes of Johannesburg, a relatively high incidence of endogenous anterior uveitis is found in both males and females. The pattern of uveitis seems to vary in similar racial groups in different parts of the world, so that geographic rather than racial factors are probably responsible.

Hogan (I962) suggested that epidemiological studies of uveitis should be made. To be informative he stated that the study should be done in a city with a population greater than $\frac{1}{2}$ million people. He also suggested that the study should be carried out in specific racial groups, emphasizing the need for a study in a negroid population. He stated that, in the surveys done at that time, the cases were seen by many observers, so that the criteria of diagnosis might vary, implying that if fewer observers were used the criteria of diagnosis would be more rigid. Furthermore, he felt that studies of this kind should not be done in uveitis clinics as the cases tend to be recurrent, severe, or chronic.

In our study of uveitis many of the criteria indicated by Hogan have been fulfilled. We have examined a specific racial group derived from a population of more than 500,000, and hope thereby to have provided an incidence study that may be used in a comparative way by other investigators. 


\section{References}

BeNNETt, G. (1955) Brit. J. Ophthal., 39, 727

BUDDEN, F. H. (1955) Ibid., 39, 32 I

GHESTERTON, J. R., and PERKINS, E. S. (1967) Ibid., 51, 6 I 7

Darrell, R. W., Wagener, H. R. and kurland, L. T. (1962) Arch. Ophthal. (Chicago), 68, 502

fajardo, R. v. (1969) Philipp. J. Ophthal., r, 46

GUYTON, J. s., and woods, A. c. (I94I) Arch. Ophthal. (Chicago), 26, 983

HOGAN, M. J. (1962) Ibid., 68, 440

, Kimura, s. J., and thygeson, P. (1959) Amer. F. Ophthal., 47, no. 5, pt 2, p. 155

kimura, s. J., hogan, M. J., and thygeson, P. (1954) AMA Arch. Ophthal., 51, 80

PERKINS, E. S. (1968) "Uveitis Survey at the Institute of Ophthalmology, London", in "Clinical Methods in Uveitis”, ed. S. Aronson, C. N. Gamble, E. K. Goodner, and G. R. O’Connor, p. 58. Mosby, St. Louis

SMith, C., and AShton, N. (1955) Brit. F. Ophthal., 39, 545

STANWORTH, A., and MCINTYRE, H. (1957) Ibid., 41, 385 